\title{
ATIVIDADE DE
}

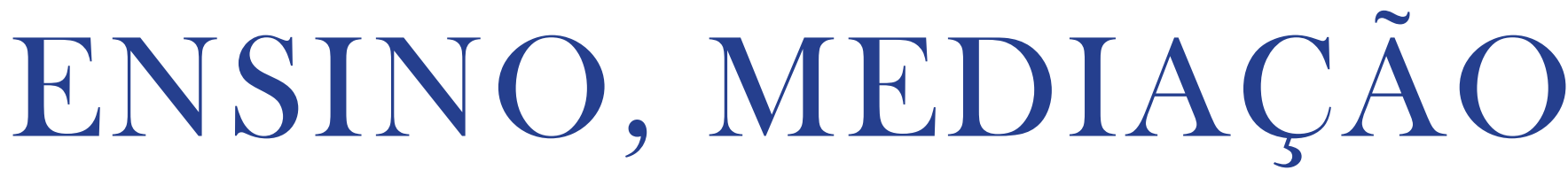

E APRENDIZAGEM

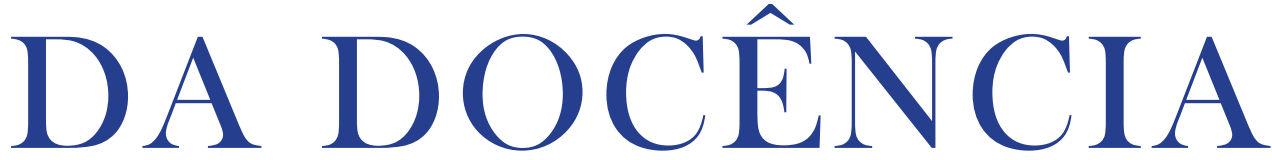

NA RESIDÊNCIA

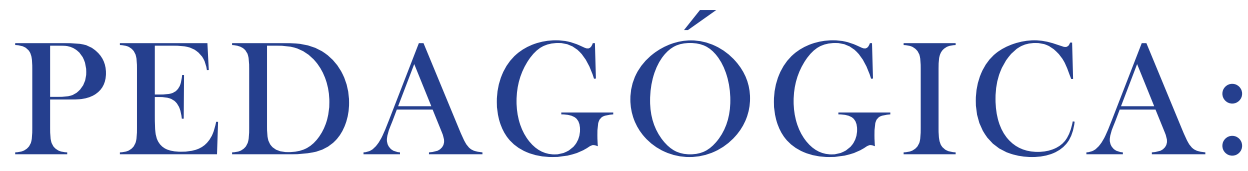

UMA ANÁLISE A

PARTIR DA TEORIA
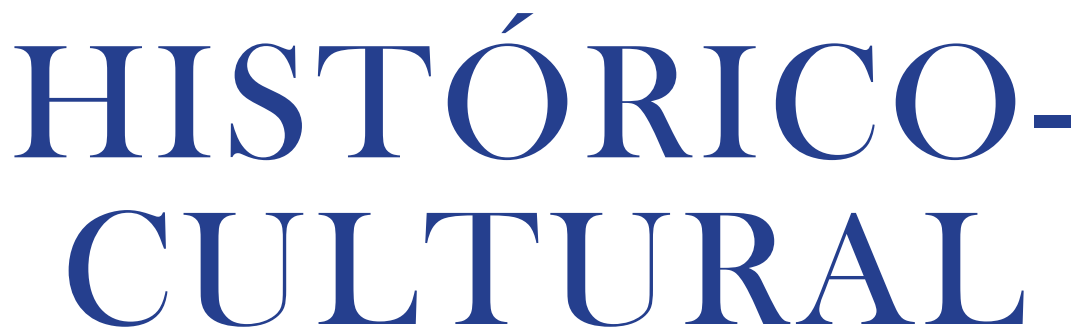

TEACHING ACTIVITY, MEDIATION AND TEACHER LEARNING IN A TEACHING RESIDENCY PROGRAM: AN ANALYSIS BASED ON CULTURALHISTORICAL THEORY

LA ACTIVIDAD DE ENSEÑNAZA, MEDIACIÓN Y APRENDIZAJE DE LA DOCENCIA EN LA RESIDENCIA PEDAGÓGICA: UN ANÁLISIS A PARTIR DE LA TEORÍA HISTÓRICO CULTURAL

Vanessa Dias Moretti

Doutora em Educação pela USP. Docente do Programa de Pós-Graduação em Educação da UNIFESP. 


\section{Edna Martins}

Doutora em Educação pela PUC/SP. Docente do Programa de PósGraduação em Educação da UNIFESP.

Docente do Programa de Pós-Graduação em Educação Universidade Federal de São Paulo (UNIFESP) Guarulhos - SP - Brasil

\section{Endereço:}

Estrada do Caminho Velho, 333 Bairro dos Pimentas - Guarulhos - SP

CEP: 07252-312

E-mails: vanessa.moretti@unifesp.br edna.martins@unifesp.br

Resumo: A partir dos pressupostos da teoria históricocultural, a pesquisa apresentada investiga o movimento de aprendizagem da docência desencadeado em estudantes do curso de Pedagogia da universidade pública do Estado de São Paulo, Brasil, por uma proposta específica de estágio supervisionado - o Programa de Residência Pedagógica (PRP). Partindo das categorias atividade de ensino e mediação, foram analisados o processo de elaboração do Plano de Ação Pedagógica (PAP) e os relatos das vivências dos residentes em um Diário de Campo on-line. A análise da produção do PAP evidencia que a aprendizagem da organização do ensino é possível no contexto do PRP ao ser desencadeada por elementos que têm constituído esse modelo de estágio: a necessidade instaurada de produção do PAP e a imersão contínua no ambiente escolar. A mediação configura-se como um elemento essencial à 
aprendizagem docente, ao permitir que, ao compartilhar experiências diárias no contexto escolar, o estudante tenha suas aprendizagens marcadas pela mediação de outros, ao mesmo tempo em que também medeia a aprendizagem dos colegas. Por meio da unidade entre aspectos cognitivos e afetivos, a aprendizagem da docência vai se constituindo de forma mediada e em atividade de ensino no espaço propiciado pela Residência Pedagógica.

Palavras-chave: Ambientes Virtuais. Aprendizagem da Docência. Teoria histórico-cultural.

Abstract: Based on the premises of Cultural-Historical Theory, this study investigates the learning movement triggered in students of the Faculty of Education, in a public university in the State of São Paulo, Brazil, for a specific proposal for supervised practice, called the Teaching Residency Program (TRP). Based on the categories teaching activity and mediation, we analyzed the process of preparing the Educational Action Plan (EAP) and the reports of students' experience in an online Field Diary. The analysis of production of EAP shows that the organization of teaching learning is possible in the context of TRP when triggered by elements that have formed the basis of this model of internship: the established need for EAP production and continuousimmersion in the school environment. Mediation is configured as an essential element of teacher learning, as it allows the student, through sharing daily experiences in the school, to have their learning marked by the mediation of others, while at the same time, mediating the learning of their colleagues. Through the unity between cognitive and affective aspects, teacher learning is constructed in a mediated form, through the teaching activity, in the space provided by the TRP. 
Key words: Virtual environments. Teacher Education. Cultural-Historical Theory.

Resumen: A partir de los supuestos de la teoría histórico cultural, el presente trabajo investiga el movimiento de aprendizaje de la docencia iniciado por una propuesta particular para la práctica supervisada - el Programa de Residencia Pedagógica (PRP) - en estudiantes del curso de Pedagogía de una universidad pública del Estado de São Paulo, Brasil. A partir de las categorías de la actividad de ensenãnza y la mediación, se analizó el proceso de elaboración del Plan de Acción Pedagógica (PAP) y los informes de las experiencias de los estudiantes en un diario virtual. El análisis de la producción del PAP muestra que el aprendizaje de la organización de la enseñanza es posible en el contexto del PRP cuando es activado por elementos que han constituido ese modelo de residencia: la necesidad establecida para la producción del PAP y la inmersión continua en el entorno escolar. La mediación se presenta como un elemento esencial para el aprendizaje de la docencia al permitir, por el intercambio de experiencias cotidianas en el contexto escolar, que el estudiante marque su aprendizaje a través de la mediación de los demás, al mismo tiempo en que hace la mediación en el aprendizaje de sus compañeros. A través de la unidad de los aspectos cognitivos y afectivos, el aprendizaje de la docencia se va constituyendo de una forma mediada por la actividad de enseñanza en el espacio proporcionado por la Residencia Pedagógica.

Palabras clave: Ambientes virtuales. Aprendizaje de la docencia. Teoría histórico cultural. 


\section{UM MODELO DE ESTÁGIO SUPERVISIONADO: O PROGRAMA DE RESIDÊNCIA PEDAGÓGICA}

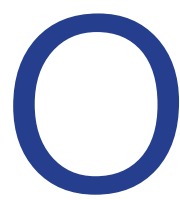

s programas de formação inicial de professores têm se debatido sobre o desafio constante de tornar a prática do estágio obrigatório significativa para a formação e aprendizagem docente. Esse desafio é particularmente ampliado para os cursos de licenciatura em Pedagogia no Brasil, uma vez que as trezentas horas destinadas ao estágio supervisionado, pelas Diretrizes Curriculares Nacionais para o Curso de Pedagogia (BRASIL, 2006), devem contemplar a formação do estudante para a gestão educacional, para a pesquisa em educação e para a docência em Educação Infantil e nas primeiras séries do Ensino Fundamental, transitando ainda pela educação de jovens e adultos e pela educação de portadores de necessidades especiais.

A busca pela superação do modelo tradicional de estágio, no qual o estudante acompanhava esporadicamente aulas em diversas classes e observando diferentes professores sem um comprometimento com o percurso de uma turma de alunos ou mesmo com a proposta de trabalho de um professor, tem levado à produção de propostas diferenciadas de estágios supervisionados. Neste contexto, surge a proposta do Programa de Residência Pedagógica (PRP) do curso de Licenciatura em Pedagogia em uma universidade pública de São Paulo, Brasil.

Nesse modelo diferenciado de estágio supervisionado e compartilhado, os estudantes em grupos, de no máximo oito, têm a experiência de imersão para quatro modalidades distintas: docência em educação infantil (105 horas), docência em ensino fundamental (105 horas), docência em educação de jovens e adultos (45 horas) e gestão educacional (45 horas). Segundo Moretti (2011):

No caso da Residência Pedagógica em docência, propõe-se que os residentes realizem um estágio de imersão cotidiana na escola durante aproximadamente um mês, acompanhando o horário de permanência do professor na instituição. Durante este período, além de colaborar com o professor em sala de aula dentro de suas possibilidades de aprendiz, o estudante também o acompanha na realização de suas diferentes atividades tais como reuniões de planejamento, reuniões de pais, avaliações de alunos, conselhos de classe etc. Outro elemento que potencializa uma aprendizagem sobre a docência bastante relevante é a experiência de regência que parte da elaboração de um Plano de Ação Pedagógica (PAP) definido de forma colaborativa entre residente, professor-formador (escola) e professor-preceptor (Universidade). (MORETTI, 2011, p.386).

Em todas as modalidades de imersão incluídas no PRP os estudantes são orientados por um docente da Universidade (preceptor) em reuniões semanais de preceptoria, bem como têm suas propostas iniciais de Plano de Ação Pedagógica 
(PAP) reelaboradas após sua apresentação ao grupo de residentes do qual faz parte, ao preceptor e ao grupo de professores na escola campo, em horário de trabalho coletivo na escola, denominada nas escolas da rede municipal local de hora-atividade (H.A.). Além disso, os residentes elaboram ao longo do período de imersão um diário de campo que tem por objetivo proporcionar a reflexão das experiências cotidianas na escola, por meio do registro e posterior análise e nova atribuição de sentido às mesmas.

Assim como o termo residência, o substantivo preceptor também foi cunhado nos espaços da medicina e aparece permeado pelos mesmos sentidos apontados por essa área. Segundo Botti e Rego (2008), a palavra preceptor vem do latim praecipio, e significa "mandar com império aos que the são inferiores". Desde o século XVI é usada para designar aquele que dá preceitos ou instruções, educador, mentor, instrutor. Com o passar do tempo o termo preceptor passou a ser usado para identificar a pessoa que educa uma criança ou um jovem, geralmente na casa do educando. Assim como na residência em medicina, o preceptor da residência pedagógica tem a função primordial de dar orientação e suporte ao graduando em sua experiência de estágio de modo que sua mediação, como "parceiro mais capaz" (VYGOTSKY, 2002), favoreça a aprendizagem da docência durante o seu processo de formação visando, sobretudo, ao bom exercício da profissão docente.

A partir de um referencial teórico apoiado nas contribuições da Teoria HistóricoCultural, pesquisadoras diretamente envolvidas nas atividades de preceptoria realizaram uma pesquisa que teve por objetivo investigar o desenvolvimento da aprendizagem de elementos da docência no espaço de formação propiciado pelo Programa de Residência Pedagógica.

\section{METODOLOGIA}

Vygotsky (1995) aponta que, em um estudo científico, o delineamento do problema de pesquisa e a escolha do método adequado para análise dos dados se desenvolvem em um movimento conjunto, de forma imbricada, de modo que a busca do método constitui tarefa fundamental em qualquer investigação de natureza científica. O método, portanto, além de ser adequado ao objeto e ao fenômeno que se deseja investigar, deve ser considerado "ao mesmo tempo premissa e produto, ferramenta e resultado da investigação" (VYGOTSKY, 1995, p. 47). 
Bernardes (2010), ao debater sobre os pressupostos da pesquisa sobre o psiquismo humano, aponta que o enfoque da Psicologia histórico-cultural fundamentado no método materialista histórico dialético visa:

[...] à superação das condições instituídas na realidade para além da crítica aos elementos próprios da sociedade, buscando identificar, na historicidade dos fenômenos estudados, as condições necessárias para que a potencialidade do gênero humano se objetive na individualidade dos sujeitos. Assim, o estudo da conduta do homem vinculase diretamente às condições objetivas criadas pela vida em sociedade. (BERNARDES, 2010, p. 299-300).

Buscando tal superação, esse trabalho utiliza como fonte de investigação registros de observação participante sobre uma determinada realidade vivida e historicamente situada, realidade essa que é significada por estudantes inseridos no Programa de Residência Pedagógica nas modalidades de Educação Infantil e de Ensino Fundamental. O instrumento de registro de observações e vivências cotidianas na escola, que chamamos de "diário de campo on-line", possui o formato de $B \log$ de acesso restrito, e é construído coletivamente pelos preceptores e estudantes de cada grupo de residentes vinculados a uma escola e por um período específico.

As observações do cotidiano vivenciado pelos alunos na escola são registradas por meio de narrativas que são editadas em forma de postagens com frequência mínima de três por semana. Os estudantes são orientados a omitirem os nomes dos atores envolvidos, tanto de professores das escolas participantes do programa de residência, quanto de crianças. A cada postagem registrada no diário de campo on-line, os preceptores e outros alunos do grupo têm a liberdade e são incentivados a postarem comentários ou oferecerem subsídios para que o residente possa construir reflexões sobre suas observações e imersão na escola. Ressaltamos que as observações registradas pelos residentes não possuem temas específicos e são decorrentes das inquietações do aluno a partir de suas vivências e interações cotidianas na escola. Em uma análise inicial, observamos que a maioria dos registros escritos encontra-se recorrentemente alicerçada por temáticas que variam desde a discussão sobre a questão da disciplina na escola, perpassando a rotina diária das turmas, brincadeiras e brinquedos, práticas educativas, até a reflexão sobre as relações entre as famílias e a escola.

Utilizamos como amostra para essa investigação as postagens realizadas no "diário de campo online" pelos alunos participantes no primeiro semestre do 
ano de 2011 com quatro grupos de seis alunos na modalidade de educação infantil e um grupo de seis alunos no primeiro semestre de 2012 na modalidade de ensino fundamental.

Para esta pesquisa foram triadas 319 postagens dos "diários de campo online" do grupo de educação infantil e 95 do grupo de ensino fundamental. Estabelecemos como critério de seleção dos dados para análise as narrativas que sofreram a interlocução dos alunos com seus colegas e com seus preceptores, por meio de postagens de comentários, e chegamos a um total de 136 postagens. Neste artigo elencamos alguns excertos de uma parte desses registros, os quais consideramos propícios para a análise e compreensão do fenômeno estudado.

\section{CONSTRUINDO A PESQUISA: O MÉTODO DE ANÁLISE DA INVESTIGAÇÃO}

A pesquisa proposta assume o objetivo de investigar o movimento de aprendizagem da docência desencadeado, em estudantes do curso de Pedagogia, por uma proposta específica de estágio supervisionado e em um período definido de tempo. Sendo o objeto da pesquisa a aprendizagem docente, a proposta é estudá-lo em movimento uma vez que "é somente em movimento que um corpo mostra o que é" (VYGOTSKY, 2002, p.86). Assim, assumimos o método histórico-dialético como método de investigação. Como categorias iniciais de análise escolhemos a atividade de ensino e a mediação por entendermos que são conceitos essenciais à compreensão do movimento de aprendizagem docente a partir de uma análise deste processo amparada na teoria histórico-cultural. Tais categorias têm sido investigadas em duas unidades de análise: as propostas de PAP e o Diário de Campo on-line. Nas duas unidades de análise buscam-se dados que revelem o movimento de aprendizagem dos estudantes em atividades de ensino e em situações de mediação que permitissem a atribuição de novos sentidos a noções relacionadas à atividade docente.

Uma vez que os dados relevantes à pesquisa se inserem em um conjunto mais amplo de dados cuja existência independe dos objetivos desta pesquisa uma vez que se vinculam às exigências acadêmicas relacionadas ao período de imersão dos estudantes em PRP -, temos que o processo de coleta de dados alia-se em um primeiro momento ao processo de análise. Ou seja, os dados 
selecionados no todo do fenômeno para constituir o universo de dados da pesquisa já se mostram como o resultado de um olhar do pesquisador no sentido de identificar o que se relaciona com o objetivo posto para a pesquisa.

Na relação entre coleta e análise de dados novamente se expressa o método de investigação na perspectiva histórico-dialética no qual os dados constroemse na relação com objetivo da pesquisa e com a intencionalidade da análise. Assim, coleta e análise de dados constituem uma unidade dialética do método.

\section{A APRENDIZAGEM DA DOCÊNCIA EM ATIVIDADE DE ENSINO}

Um elemento chave do processo de imersão no PRP é a elaboração do Plano de Ação Pedagógica (PAP). Embora a elaboração desse plano esteja vinculada à experiência de regência, exigência bastante comum a diferentes modelos de estágios supervisionados, no PRP essa exigência assume um cunho diferenciado ao configurar-se de forma articulada com o trabalho colaborativo que caracteriza sua elaboração. Além disso, sendo uma das exigências do programa, a elaboração do PAP impõe aos estudantes a necessidade de organizar o ensino diante da realidade cotidiana da sala de aula. Os estudantes evidentemente respondem de formas e qualidades diversas a essa necessidade. Alguns, de fato, cumprem a proposta como resposta a uma exigência externa a eles apenas como forma de garantir a validação do seu estágio, mas o motivo que os leva a agir não é o resultado de suas ações. No entanto, há casos nos quais essa exigência externa move o sujeito para a organização de ações que lhe permite atribuir novos sentidos a sua atividade de organização do ensino por meio da elaboração do PAP.

O processo de mudança de sentido atribuído a essa atividade pode ser mais bem analisado a partir das contribuições teóricas da psicologia históricocultural. Em particular, a Teoria da Atividade proposta por Leontiev (2001) nos fornece subsídios para compreender a estrutura das atividades dos sujeitos, entendidas como processo psicológico, e o movimento de mudança de sentido pessoal articulado a essa atividade. Para Leontiev, atividades são "processos psicologicamente caracterizados por aquilo a que o processo, como um todo, se dirige (seu objeto), coincidindo sempre com o objetivo que estimula o sujeito a executar esta atividade, isto é, o motivo" (LEONTIEV, 2001, p.68). Para esse autor, é na atividade que o sujeito atribui sentido pessoal às significações 
sociais. No entanto, o conceito de atividade não se confunde com a mera ação, embora dela não prescinda.

A atividade assim compreendida nasce sempre de uma necessidade que, por sua vez, objetiva-se materialmente no motivo da atividade, no que lhe confere direção. No processo de objetivação da necessidade, ou seja, de produção do objeto da atividade, o homem organiza ações, relacionadas ao objetivo desta atividade, e operações vinculadas às condições objetivas de sua realização. É importante destacar que há um movimento possível entre ações e atividade que permite que uma ação, ao ganhar um motivo, seja transformada em atividade e, ao contrário, uma atividade ao perder o seu motivo se transforme em uma ação dentro de outra atividade que a englobe (LEONTIEV, 2001).

No contexto do PRP e, especificamente, no processo de elaboração do PAP, esse movimento de transformação de ação em atividade pode ser observado por meio dos motivos expressos pelos estudantes. Em geral, a produção do PAP inicia-se como uma ação vinculada a uma exigência externa ao estudante, colocada pelo PRP, na figura no preceptor. A produção do PAP, neste contexto, não pode ser considerada como uma atividade para o estudante. No entanto, em alguns casos, os estudantes atribuem novo sentido ao PAP durante seu processo de produção. Segundo Leontiev (2001), o sentido pessoal está sempre relacionado com o motivo da atividade. Sendo assim, no caso dos estudantes, se a atribuição de novo sentido pessoal ao PAP relaciona-se com a atribuição de motivo à ação de elaboração do PAP, temos que essa ação transforma-se em atividade. Mais particularmente, nesse processo de nova atribuição de sentido pessoal à ação de elaboração do PAP, o estudante entra em atividade de ensino e é nessa atividade, ao buscar ações e selecionar instrumentos que permitam coincidir o seu motivo ao que será objetivado na atividade, que se dá a apropriação de elementos da docência relacionados à organização do ensino, permitindo ao estudante a aprendizagem de elementos essenciais à docência.

O caso do estudante Mateus (nome fictício) é representativo desse processo de atribuição de novo sentido pessoal ao PAP na relação com a realidade concreta do cotidiano escolar. Logo na primeira semana de imersão esse estudante revela seu estranhamento e incômodo pela forma como se dão as relações entre os alunos e entre alunos e professora: 
Toda vez que alguns alunos falam, levantam ou comentam alguma coisa em sala, outros, em geral os mais inquietos, ficam provocando os colegas, que caem nas provocações [...] Os gritos da professora me incomodam profundamente. Como ela quer que eles parem de gritar ou falem baixo, se ela mesma grita? (Mateus, Diário de Campo on-line, quarto dia de imersão).

$\mathrm{Na}$ sequência dessas observações o estudante reflete o quanto a ação intencional do educador poderia intervir nessa realidade, propiciando momentos de aprendizagens relacionadas à formação para a cidadania e conclui apontando para uma possibilidade de contribuição de um PAP que poderia "modificar ou melhorar a prática da professora e a aprendizagem dos alunos". Embora, nesse momento, ainda não haja uma proposta sobre o que fazer na regência, esses primeiros registros indicam um movimento de constituição de motivo para a atividade.

Os relatos do estudante sobre relações conflituosas entre os sujeitos em sala de aula permanecem em seu diário de campo on-line no decorrer dos dias seguintes até que ele consegue elaborar um motivo para o PAP que objetive a necessidade de intervir na forma como se estabelecem tais relações:

Creio que elaborando um PAP tratando sobre a formação de valores de respeito, principalmente, além de outros que deverão ser abordados, até mesmo a professora se sensibilizará com a questão e poderá pensar duas vezes antes de se comportar da mesma maneira, assim como os alunos, já que, pelo que eu percebo a escola não possui um projeto, nem mesmo a professora busca trabalhar essas questões. (Mateus, Diário de Campo online, oitavo dia de imersão).

A mudança de sentido com a produção de novo motivo se dá na relação do sujeito com a realidade, de forma mediada no Blog, e permite que o estudante busque ações, operações e instrumentos que viabilizem a objetivação do novo motivo em atividade. No processo de elaboração de PAP analisado, a coincidência entre o produto dessa atividade e o motivo - a construção de relações éticas entre os sujeitos - permitiu que o estudante, em atividade de ensino, organizasse ações que objetivassem o seu motivo:

[...] proponho um trabalho com bastante abertura ao diálogo, onde os alunos poderão colocar seus pontos de vista, o que se faz necessário para reflexão da turma. Serão feitas rodas de conversa a respeito de um texto [...] o qual aborda a respeito da mudança de atitudes. Também após a exibição de um vídeo [...] ainda conversaremos sobre certas imagens que demonstram situações de falta de respeito e de ética. (Mateus, Diário de Campo online, décimo sexto dia de imersão).

A proposta de regência apresentada resultou dessa forma, de um movimento de aprendizagem do estudante sobre a organização do ensino - elemento essencial à aprendizagem da docência -, que foi se constituindo 
em sua atividade de estágio, a partir de um incômodo inicial que gerou uma necessidade de intervenção na realidade. Essa necessidade, por sua vez, não seria suficiente para orientar sua atividade de elaboração de PAP. No entanto, quando essa necessidade toma forma no motivo, esse orienta a escolha de ações e instrumentos (texto, filme etc.).

\section{A MEDIAÇÃO NO “DIÁRIO DE CAMPO ON-LINE" - O BLOG DA RESIDÊNCIA PEDAGÓGICA}

Considerando a tese de Vygotsky de que a aprendizagem impulsiona ou promove o desenvolvimento dos indivíduos, Martins (2011) aponta que, ao tomarmos a inserção social de modo abrangente, poderíamos construir a hipótese de que quaisquer apropriações poderiam igualmente promover o desenvolvimento humano. Contudo, a mesma autora adverte que, "segundo Vygotsky, os conteúdos disponibilizados à apropriação encerram aspectos qualitativamente distintos, deixando claro, que nem toda aprendizagem é, de fato, promotora de desenvolvimento." (p. 218). Nesse sentido, compreendendo o processo de ensino e aprendizagem em qualquer momento do desenvolvimento humano, devemos levar em conta a forma como se selecionam qualitativamente os conteúdos, assim como se organizam os modos de aprender e ensinar. As condições em que a aprendizagem ocorre, sistemática, formal ou não formal, também não é um aspecto que deva ser deixado em segundo plano.

A preceptoria no caso da RP percorre um caminho de tentativas de intervenções que objetivamente tenham um papel de mediação na superação do saber espontâneo dos futuros professores em busca de um saber acadêmico e científico sistematizado, provocando no aluno mais do que a simples compreensão de elementos teóricos, mas buscando atingir a construção de aprendizagens significativas capazes de alinhavar a teoria aprendida nas salas de aula da universidade com a atividade prática do educador.

Vygotsky deu especial destaque ao papel dos processos colaborativos entre pares e à importância de parceiros mais experientes nos processos de aprendizagem humana. Entendemos que o professor preceptor, assim como o educador que recebe o aluno residente, são mediadores por excelência, contudo outros parceiros dos grupos de discussões, alunos que já tiveram alguma 
experiência na escola, assim como outros elementos do ambiente cotidiano da escola têm sido elementares na construção do conhecimento necessário à atividade docente. Daniels (2003), citando Davydov, aponta que o próprio Vygotsky não defendia a ideia de que a aprendizagem se dá em um contexto separado, no qual se incluiriam apenas o professor e o estudante. Todo o entorno social dinâmico que conecta o professor e o aluno deveria ser compreendido nessa relação. Desse modo, o professor "[...] deve conhecer as dinâmicas sociais particulares do cenário social da criança e saber sobre as possibilidades de sua própria atividade pedagógica para usá-las com sensibilidade e assim, elevar a um novo nível a atividade, a consciência e a personalidade de seus pupilos" (DANIELS, 2003, p. 17).

Além da importância dos processos de interação que ocorrem entre o professor e outros parceiros mais experientes na relação com o aluno, a teoria históricocultural defende que o conceito de mediação incorpora a compreensão do uso e função dos signos e dos instrumentos na formação das funções psicológicas superiores. É por meio desses elementos que ocorre o desenvolvimento psíquico, tornando possível a apropriação da experiência social e cultural da humanidade pelo aluno em desenvolvimento.

Assim como o educador medeia a aprendizagem das crianças, também os preceptores no PRP buscam mediar a aprendizagem da docência para adultos e jovens em aprendizagem da docência, apoiando-se na dinâmica do ambiente em que o estudante está imerso e na discussão e na análise das relações que permeiam o universo escolar, com vistas à produção do PAP que contemple minimamente a atividade educativa socialmente significada. Prioriza-se a unidade entre teoria e prática, de modo que a compreensão da realidade escolar se dê superando a simples observação do dia a dia da escola e considerando, além dos objetos e dos signos do ambiente, as interações vividas pelas crianças, professores e funcionários nesse espaço. Segundo Davydov:

Os pedagogos começam a compreender que a tarefa da escola contemporânea não consiste em dar às crianças uma soma de fatos conhecidos, mas em ensiná-las a orientar-se independentemente na informação científica e em qualquer outra [...] quer dizer, desenvolver ativamente neles os fundamentos do pensamento contemporâneo para o qual é necessário organizar um ensino que impulsione o desenvolvimento. (DAVÍDOV, 1988, p.3).

Numa análise mais apurada de instrumentos mediadores no PRP, o Diário de Campo on-line constitui-se como uma possibilidade efetiva de mediação 
semiótica, favorecida pelo desenvolvimento tecnológico. A seguir, apresentamos excertos que revelam momentos da aprendizagem da docência do estudante Luis, mediados pela professora preceptora.

O estudante havia planejado uma ação pedagógica cujo objetivo era explorar a noção de metamorfose animal. Assim como o aluno, a preceptora e os colegas estavam animados com a proposta. O PAP já estava em fase de "aquecimento" pela presença de um inseto que as crianças vinham observando cotidianamente e que, inesperadamente, sumiu da sala de aula. A postagem feita pelo aluno demonstra o quanto ele estava emocionalmente abalado e decepcionado com os acontecimentos do cotidiano escolar.

A lagarta que estava em nossa sala para que pudéssemos cuidar dela até que virasse uma borboleta, sumiu. Na segunda feira, segundo a professora, ela estava lá, tanto que as crianças viram. Estava viva e muito bem. Já na terça feira, ela havia sumido. Provavelmente alguém que não sabia do trabalho que estávamos fazendo, jogou a lagarta fora! As crianças sentiram muito a perda, questionavam se havia morrido, quem tinha jogado fora, por que o fizeram, o que iria acontecer. Achei total falta de bom senso, uma vez que se estava em local para que nenhuma criança alcançasse, em cima do armário, de certo não era para se jogar fora ou dar qualquer outro destino a ela que não fosse o nosso, de podermos ver o que ia acontecer. Enfim, meu desabafo foi feito. (Luis, Diário de campo on-line).

A mediação da professora preceptora, ao colocar o estudante diante de outras possíveis inquietações que poderiam fazer parte da próxima discussão do grupo, permitiu-Ihe considerar outras possibilidades de continuação para a proposta inicial trabalho pensado pelo aluno.

[...] vou me ater ao fato do sumiço da lagarta. Em primeiro lugar: Quando relatado às crianças sobre o desaparecimento da lagarta, como elas reagiram? Provavelmente se apegaram ao bichinho ou havia nelas o sentimento de perda.Caso vocês tivessem um projeto baseado na vida e transformação do bichinho, você não acha que esse seria um momento interessante para dar continuidade ao trabalho? Vocês poderiam trabalhar uma porção de questões com as crianças, desde o sentimento de perda da lagarta até mesmo as possíveis chances de ela ter sido devorada por uma lagartixa que estava de passagem. Poderiam até mesmo fazer uma investigação na escola, buscando pistas junto com as crianças. Vocês não devem desistir do projeto e sim fazer do imprevisto um elemento de continuidade de suas ações. [...] (Professora preceptora, Diário de campo on-line).

Embora diante do sumiço da lagarta o residente tivesse inicialmente perdido o foco da proposta e ficado sem saber como dar continuidade ao PAP, a partir das mediações da preceptora, ele conseguiu dar novo rumo à proposta, apropriandose tanto de outros elementos conceituais fundamentais para a abordagem de seu plano de ação, quanto de elementos da docência relacionados com 
imprevisibilidade do cotidiano escolar. De forma mediada, o estudante retoma seu projeto inicial e trabalha com a questão do "sumiço da lagarta", produzindo outros caminhos para o desenvolvimento de um plano de ação com várias dimensões. Nesse sentido, sua aprendizagem foi potencializada tanto pelo contato com a realidade escolar cotidiana quanto pela mediação estabelecida no Blog, revelando a apropriação de um saber exigido à docência em educação infantil que é justamente o saber lidar com imprevistos, buscando fazer com que os obstáculos sejam promotores de desenvolvimento para as crianças.

Hoje [...] iniciei a minha tão esperada aplicação do plano de ação pedagógica. De acordo com o cronograma e o planejamento do meu PAP, hoje o objetivo era passar os vídeos da metamorfose da borboleta do cocoricó e também a metamorfose real, montar o ambiente da lagarta e da borboleta na caixa de papelão. [...] Antes de solicitar que fizessem tal atividade, (a professora) falou que na segunda parte do dia quem iria dar a atividade iria ser eu. As crianças ficaram super felizes e surgiu um comentário que me deixou muito surpreso, pela percepção que essa criança tem da minha presença naquele local. Uma das alunas falou: - 'Ele vai aprender!' (Luis, Diário de campo on-line).

Como expressado no final do relato, Luis aprendeu muito, não só com o contato com as crianças, mas também com a mediação dos preceptores e a ajuda dos colegas com mais experiência, lhe permitindo estabelecer novas relações entre as questões teóricas trazidas da universidade e a prática docente.

A análise dos dados do Diário de Campo on-line demonstra que a mediação propiciada por este espaço virtual de aprendizagem é um elemento de múltiplas faces que pode estar presente nas multideterminações do processo educativo. Ao compartilhar experiências diárias no contexto escolar, o aluno é mediador ao mesmo tempo em que também tem suas aprendizagens marcadas pela mediação de vários outros. Aos poucos a possibilidade de se expor ao grupo vai criando necessidades de aprendizagem que sem a interlocução do outro jamais viriam à tona.

Neste contexto, a linguagem socialmente significada destaca-se como signo mediador ao promover uma ressignificação da ação do professor e dos estudantes. A linguagem como mediador privilegiado e na forma de gestos e dos sons, como palavra oral e escrita, ou ainda como linguagem externa ou interna, pode assumir funções variadas ao longo da história de desenvolvimento de cada sujeito. É por meio da linguagem socialmente significada que se dá a apropriação do conhecimento e da cultura uma vez que, segundo Vygotsky, a "linguagem não depende necessariamente de sons. [...] Em princípio, a linguagem 
não depende da natureza do material que utiliza" (VYGOTSKY, 1996, p. 33). É a partir de seu uso que podemos afirmar o caráter social do psiquismo humano. Essa força pode ser sintetizada na afirmação de Vygotsky (1997, p. 77), quando aponta que "[...] a linguagem não é só um meio de se compreender os demais, mas também de se compreender a si mesmo!".

\section{CONSIDERAÇÕES FINAIS}

A análise dos dados aponta para a aprendizagem mediada de elementos da docência em estudantes do curso de Pedagogia que vivenciaram uma proposta específica de estágio supervisionado. Tal aprendizagem se revela quando os estudantes são colocados diante da necessidade de organizar o ensino e, no processo de atividade de ensino, constituem-se mediações e interações entre os diferentes sujeitos envolvidos no processo de estágio - estudantes, professores da escola campo e docentes da universidade.

Na unidade de análise produção do PAP evidenciamos que a aprendizagem da organização do ensino é possível no contexto do PRP ao ser desencadeada pelos elementos que têm constituído esse modelo de estágio, ou seja, a necessidade instaurada de produção do PAP e a imersão contínua no ambiente escolar. A partir desses elementos, o estudante tem a possibilidade de atribuir novos sentidos à exigência de regência e, neste caso, constituir novo motivo para sua atividade que oriente uma escolha intencional de ações e instrumentos que deem conta de seu objetivo. A articulação entre esses elementos - necessidade, motivo, sentido, ação, instrumento - tal como analisada neste estudo, revela o movimento de aprendizagem de elementos da docência do estudante em atividade de ensino.

Sobre os processos de mediação, a análise do recurso do "Diário de Campo on-line" mostrou-o como uma ferramenta mediadora do processo de apropriação de conhecimento. Sua vantagem principal é que relatos da atividade diária podem ser expressos e compartilhados constantemente, sendo objeto de comentários de outros pares, o que permite a produção mediada de novos sentidos e aprendizagens. O "Diário de Campo on-line" apontou que as narrativas de cada residente não se configuram como anotações vazias guardadas para si, mas como elementos capazes de movimentar um grupo de estudantes e professores na busca de aprendizagem e de soluções para as questões colocadas no contexto da escola. 
A pesquisa revelou também que esse instrumento mediador no formato de Blog, e a possibilidade que ele oferece de o sujeito se expressar de um modo virtual, possibilitou até ao aluno mais tímido participar de atividades com os outros, possibilitando que, na unidade entre aspectos cognitivo e afetivo, a aprendizagem da docência fosse se constituindo de forma mediada em atividade de ensino, a partir das necessidades colocadas aos sujeitos no espaço da Residência Pedagógica.

O espaço virtual "Diário de Campo on-line", como ferramenta de comunicação, ofereceu ao residente a oportunidade de aprender elementos da docência na medida em que sua individualização pôde passar por um processo mediado de desenvolvimento da autonomia, da capacidade de intervenção, interpretação e criação, sobretudo nas situações em que pôde perceber que sua "fala" é respeitada, bem como as informações que traz para o grupo e, neste contexto, individual e coletivo se constituem mutuamente.

\section{REFERÊNCIAS}

BOTTI, S. H. de O; REGO, S. Preceptor, supervisor, tutor e mentor: quais são seus papéis? Rev. bras. educ. med. [on-line], vol.32, n.3, pp. 363-373, 2008.

BRASIL.CNE/CP. Parecer $n^{\circ} 1$, de 15 de maio de 2006. Diretrizes Curriculares Nacionais para o Curso de Graduação em Pedagogia, licenciatura. Disponível em http://portal.mec.gov.br/cne/arquivos/pdf/rcp01_06.pdf. Acesso em: 23 de maio de 2012.

DAVÍDOV, V. La enseñanza escolar y el desarrollo psíquico. Prefácio. Moscu, Editorial Progreso, 1988.

LEONTIEV, A. N. Uma contribuição à teoria de desenvolvimento da psique infantil. In: VIGOTSKII, L. S. et al. Linguagem, desenvolvimento e aprendizagem. São Paulo: Ícone, Cap. 4, p. 59-83, 2001.

LIBÂNEO, J. C. A didática e a aprendizagem do pensar e do aprender: a teoria histórico- cultural da atividade e a contribuição de Vasili Davydov. Revista Brasileira de Educação, Rio de Janeiro, n. 27, 2004.

MARTINS, L. M. O desenvolvimento do psiquismo e a educação escolar: contribuições à luz da psicologia histórico cultural e da pedagogia histórico-crítica. Tese de Livre docência. Departamento de Psicologia da Faculdade de Ciências da Universidade Estadual Paulista, Bauru, 2011.

MORETTI, V. D. A articulação entre a formação inicial e continuada de professores 
que ensinam matemática: o caso da Residência Pedagógica da Unifesp. Revista Educação. Porto Alegre, 2011, v. 34, n. 3, p. 385-390, set./dez. 2011

VYGOTSKY, L. S. Pensamento e linguagem. São Paulo: Martins Fontes, 1996.

VIGOTSKI, L. S. A formação social da mente. 6. ed. São Paulo: Martins Fontes, 2002.

Artigo recebido em 24/09/2014 Aprovado em 04/03/2015 